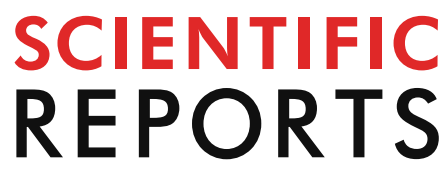

natureresearch

Check for updates

\title{
Molecular detection
} and phylogenetic analyses of Wolbachia in natural populations of nine galling Aphid species

\author{
Weibin Ren ${ }^{1}$, Hongyuan $\mathrm{Wei}^{1}$, Ying Yang ${ }^{1}$, Shuxia Shao ${ }^{1,2}$, Haixia Wu ${ }^{1,2}$, Xiaoming Chen $^{1,2}$ \& \\ Zixiang Yang ${ }^{1,2 \bowtie}$
}

Wolbachia is one of the most abundant facultative intracellular symbionts in arthropods. It alters host biology in diverse ways, including the induction of reproductive manipulation, association of nutrient supplier and protection against pathogens. Aphids are a group of insects which exhibit interesting biological characteristics such as complex life cycles, alteration of sexual and asexual reproduction and shifts between two different hosts. Wolbachia is widely present in many orders of insects, but so far limited studies on Wolbachia in aphids have been carried out. Galling aphids are a group of aphids that induce galls on their primary host plants at specific life stage. In this study, 15 natural populations representing nine galling aphid species were analyzed for the presence of Wolbachia using species-specific primer pairs. Wolbachia presence in galling aphids was quite low and varied significantly among aphid populations. Only three of the 15 populations we analyzed had detectable Wolbachia and the overall infection rate was $20 \%$. Two Wolbachia strains, $O$ and B, were identified from the galling aphids Kaburagia rhusicola and Schlechtendalia chinensis. Strain O was for the first time to be found in aphids, and it is likely involved with the life stages of galling aphids living in closed microenvironments with specific survival strategies that are different from free-living aphids.

Wolbachia is an intracellular facultative symbiont present widely in arthropods. Wolbachia species such as Wolbachia pipientis have many different strains ${ }^{1,2}$. At present, 16 Wolbachia supergroups have been reported, and named $\mathrm{A}$ to $\mathrm{F}$ and $\mathrm{H}$ to $\mathrm{Q}$ from insects ${ }^{3-6}$. Wolbachia diversity was initially characterized using the genes wsp, 16S $r R N A$, ftsZ, gltA, and groEL as molecular markers ${ }^{7}$. One of the consequences of Wolbachia in insects is associated with the induction of different reproductive strategies such as parthenogenesis, feminization, male-killing and cytoplasmic incompatibility $(\mathrm{CI})^{8-11}$. In addition to reproduction, Wolbachia can also affect the biological characteristics of its hosts, such as providing host nutrients, protecting hosts from RNA viruses, regulating the age structure of the host populations, and improving the proliferation of host stem cells ${ }^{13-16}$. The presence of Wolbachia in insects may put selective pressure more strongly on a host or create reproductive barriers that can lead to speciation. Wolbachia-based methods have also been developed to control the transmission of insect pests and arboviruses ${ }^{17,18}$. Aphids are a group of insects, many of which are important pests for agriculture and forestry ${ }^{18,19}$. However, some species such as galling aphids can manipulate to plant tissues, resulting in the formation of galls, which can provide protection for aphids from predators ${ }^{20-22}$. Like most aphids, galling aphids exhibit complex biological traits and a complicated life cycle, such as sexual and asexual reproduction, and alternating between two host species ${ }^{23}$. Among galling aphids, Chinese galling aphids are specific species which induce closed galls rich in tannins on Chinese sumac trees (Anacardiaceae: Rhus) and have been used for medicinal, chemical and other industrial purposes ${ }^{23,24}$.

Until recently, aphids were thought to be free of Wolbachia $^{26-29}$. However, data on European aphids indicate that the absence of Wolbachia was an underestimate ${ }^{3}$. A total of 425 natural samples representing 144 aphid species have been analyzed for the presence of Wolbachia using specific $16 S$ rRNA-based PCR, and 37 (8.7\%) samples have been found to have Wolbachia $^{3}$. Later in China, 109 samples representing 73 aphid species have also

${ }^{1}$ Research Institute of Resource Insects, Chinese Academy of Forestry, Kunming, China. ${ }^{2}$ Key Laboratory of Cultivating and Utilization of Resources Insects, State Forestry Administration, Kunming, China. ${ }^{\square}$ email: yzx1019@163.com 


\begin{tabular}{|c|c|c|c|c|c|c|c|c|c|c|c|c|c|c|}
\hline \multirow[b]{3}{*}{ Aphid species } & \multirow[b]{3}{*}{ Primary host } & \multirow{3}{*}{$\begin{array}{l}\text { Collected } \\
\text { location }\end{array}$} & \multicolumn{10}{|c|}{ Wolbachia infection prevalence } & \multirow{3}{*}{$\begin{array}{l}\text { Number } \\
\text { of tested } \\
\text { populations }\end{array}$} & \multirow{3}{*}{$\begin{array}{l}\text { Number } \\
\text { of infected } \\
\text { populations }\end{array}$} \\
\hline & & & \multirow[b]{2}{*}{$16 S$ rRNA } & \multicolumn{5}{|c|}{ MLST genes } & \multicolumn{3}{|c|}{ Other genes } & \multirow[b]{2}{*}{ Supergroup } & & \\
\hline & & & & gat $B$ & $f b p A$ & $\operatorname{coxA}$ & hcpA & ftsZ & wsp & gltA & groEL & & & \\
\hline \multirow{5}{*}{$\begin{array}{l}\text { Kaburagia } \\
\text { rhusicola }\end{array}$} & \multirow{5}{*}{ Rhus potaninii } & $\begin{array}{l}\text { Yunnan Kun- } \\
\text { ming }\end{array}$ & + & + & + & - & - & - & - & - & - & $\mathrm{O}$ & 6 & 4 \\
\hline & & \begin{tabular}{|l} 
Shaanxi \\
Chenggu
\end{tabular} & - & - & - & - & - & - & - & - & - & - & 6 & 0 \\
\hline & & $\begin{array}{l}\text { Shaanxi Ning- } \\
\text { qiang }\end{array}$ & - & - & - & - & - & - & - & - & - & - & 6 & 0 \\
\hline & & Yunman Yanjin & - & - & - & - & - & - & - & - & - & - & 6 & 0 \\
\hline & & Sichuan Emei & - & - & - & - & - & - & - & - & - & - & 6 & 0 \\
\hline $\begin{array}{l}\text { Floraphis meit- } \\
\text { anensis }\end{array}$ & $\begin{array}{l}\text { Rhus punjaben- } \\
\text { sis var. sinica }\end{array}$ & $\begin{array}{l}\text { Yunnan Kun- } \\
\text { ming }\end{array}$ & - & - & - & - & - & - & - & - & - & - & 9 & 0 \\
\hline $\begin{array}{l}\text { Schlechtendalia } \\
\text { peitan }\end{array}$ & Rhus chinensis & $\begin{array}{l}\text { Yunnan Kun- } \\
\text { ming }\end{array}$ & - & - & - & - & - & - & - & - & - & - & 9 & 0 \\
\hline Nurudea shiraii & Rhus chinensis & $\begin{array}{l}\text { Yunnan Kun- } \\
\text { ming }\end{array}$ & - & - & - & - & - & - & - & - & - & - & 9 & 0 \\
\hline \multirow{3}{*}{$\begin{array}{l}\text { Schlechtendalia } \\
\text { chinensis }\end{array}$} & \multirow{3}{*}{ Rhus chinensis } & $\begin{array}{l}\text { Yunnan Kun- } \\
\text { ming }\end{array}$ & - & - & - & - & - & - & - & - & - & - & 9 & 0 \\
\hline & & Hubei Wufeng & - & - & - & - & - & - & - & - & - & - & 9 & 0 \\
\hline & & Sichuan Emei & + & + & + & - & - & - & - & - & - & $\mathrm{O}$ & 9 & 1 \\
\hline $\begin{array}{l}\text { Pemphigus } \\
\text { yangcola }\end{array}$ & $\begin{array}{l}\text { Populus yun- } \\
\text { nanensis }\end{array}$ & $\begin{array}{l}\text { Yunnan Kun- } \\
\text { ming }\end{array}$ & - & - & - & - & - & - & - & - & - & - & 6 & 0 \\
\hline $\begin{array}{l}\text { Pemphigus yun- } \\
\text { nanensis }\end{array}$ & $\begin{array}{l}\text { Populus yun- } \\
\text { nanensis }\end{array}$ & $\begin{array}{l}\text { Yunnan Kun- } \\
\text { ming }\end{array}$ & + & + & + & + & + & + & - & - & - & B & 9 & 1 \\
\hline $\begin{array}{l}\text { Pemphigus } \\
\text { populitrans- } \\
\text { versus }\end{array}$ & $\begin{array}{l}\text { Populus yun- } \\
\text { nanensis }\end{array}$ & $\begin{array}{l}\text { Yunnan Kun- } \\
\text { ming }\end{array}$ & - & - & - & - & - & - & - & - & - & - & 9 & 0 \\
\hline $\begin{array}{l}\text { Chaetogeoica } \\
\text { folidentata }\end{array}$ & $\begin{array}{l}\text { Pistacia chin- } \\
\text { ensis }\end{array}$ & $\begin{array}{l}\text { Yunnan Chux- } \\
\text { iong }\end{array}$ & - & - & - & - & - & - & - & - & - & - & 9 & 0 \\
\hline
\end{tabular}

Table 1. Sample for the study of Wolbachia infection in galling aphid. +, amplification; -, failed to detect amplification product.

been analyzed, and all the samples have been found to have Wolbachia ${ }^{4}$. Wang et al. $(2014)^{2}$ suggested that the infection status of Wolbachia in aphid populations from China might differ from other areas and this multiple infection pattern was probably caused by horizontal transmission ${ }^{2,30,31}$. However, horizontal transmission has not been observed in European aphids.

So far, four Wolbachia supergroups, A, B, M and $\mathrm{N}$ have been detected in aphids with supergroup $\mathrm{M}$ being the most commonly detected ${ }^{3}$. The distribution patterns of Wolbachia in Chinese aphids are complex and varied among different species ${ }^{4}$. Wolbachia in aphids is underestimated primarily because of its low titer and/or high divergence of different strains. Among the 217 aphid species analyzed for Wolbachia before, only 11 were galling aphids (4.1\%), and of those, only six galling aphids carried Wolbachia ${ }^{3,4}$. Therefore, the distribution of Wolbachia in galling aphids and its significance remain to be studied.

The objective of this study is to investigate the presence of Wolbachia in natural populations of galling aphids from China. Specifically, Wolbachia strains were screened and classified based on nine marker genes: $16 S$ rRNA, gltA, groEL, wsp, gat B, fbpA, coxA, hcpA and $f t s Z$. Phylogenetic analysis was also conducted based on the sequences of the marker genes.

\section{Results}

Screening for Wolbachia in natural populations of galling Aphids. A total of 117 samples of natural galling aphids were collected from various host plants in 7 different locations in China. The 117 samples represented 15 populations of 9 aphid species within 6 genera, 2 tribes of Aphididae. The 15 populations were from genera Kaburagia (1 species, 5 populations), Floraphis (1 species, 1 populations), Schlechtendalia ( 2 species, 4 populations), Nurudea (1 species, 1 populations), Pemphigus (3 species, 3 populations), and Chaetogeoica (1 species, 1 populations) (Table 1). All samples were screened for the presence of Wolbachia by PCR amplification using $16 S$ rRNA-specific primers 16S-281F/1372R. Our results showed that the presence of Wolbachia in these populations was infrequent and varied significantly among different aphid populations. Among all 15 aphid populations, only 3 populations were detected to harbor Wolbachia. These Wolbachia-carrying aphids were Kaburagia rhusicola and Schlechtendalia chinensis from the tribe Fordini, and Pemphigus yunnanensis from the tribe Pemphigini. No Wolbachia was detected in the remaining populations. Among the Wolbachia-positive species, Wolbachia was detected in four out of six samples in K. rhusicola, and in one out of nine samples in either S. chinensis or P. yunnanensis (Table 1).

Sequence variation in Wolbachia genes. Nine genes including $16 S$ rRNA, gltA, groEL, wsp, gatB, fbpA, $\operatorname{cox} A, h c p A$ and $f t s Z$ of Wolbachia were selected for PCR amplification. However, only six genes were amplified 


\begin{tabular}{|c|c|c|c|c|c|c|}
\hline \multirow[b]{3}{*}{ Aphids and collected location } & \multicolumn{6}{|c|}{ Gene names } \\
\hline & \multirow[b]{2}{*}{$16 S r R N A$} & \multicolumn{5}{|c|}{ MLST genes } \\
\hline & & gatB & $f b p A$ & $\operatorname{cox} A$ & hсpA & ftsZ \\
\hline Kaburagia rhusicola Kunming & 1,077 & 497 & 476 & - & - & - \\
\hline Schlechtendalia chinensis Emei & 1,061 & 492 & 479 & - & - & - \\
\hline Pemphigus yunnanensis Kunming & 1,054 & 497 & 480 & 488 & 509 & 518 \\
\hline
\end{tabular}

Table 2. Gene sequence lengths of Wolbachia infected in the galling aphids.

from at least one of the three populations harboring Wolbachia. Three genes including $16 S \mathrm{r} R \mathrm{NA}$, gat $B$ and $f b p A$ were amplified from K. rhusicola and S. chinensis. The amplicon lengths were 1,077 bp for $16 S \mathrm{rRNA}, 497 \mathrm{bp}$ for $g a t B$, and $476 \mathrm{bp}$ for $f b p A$ for samples from $K$. rhusicola, whereas the amplicons were 1,061 bp for $16 S \mathrm{rRNA}$, $492 \mathrm{bp}$ for $g a t B$, and $479 \mathrm{bp}$ for $f b p A$ for samples from the $S$. chinensis. Six genes including $16 S \mathrm{r} R N A, g a t B, f b p A$, $\operatorname{coxA}, h c p A$ and $f t s Z$ were amplified from the P. yunnanensis. The amplicon sizes were 1,054 bp for $16 S \mathrm{rRNA}$, $497 \mathrm{bp}$ for $g a t B, 480 \mathrm{bp}$ for $f b p A, 488 \mathrm{bp}$ for $\operatorname{coxA}, 509 \mathrm{bp}$ for $h c p A$, and $518 \mathrm{bp}$ for $f t s Z$ (Table 2).

Phylogenetic analysis. A phylogenetic analysis was conducted based on the partial 16S rRNA gene sequences (about 1,100 bp). Two different groups were revealed. The Wolbachia strains detected from K. rhusicola and S. chinensis clustered within supergroup O with high bootstrap support (90/99), while strains detected from the P. yunnanensis clustered with supergroup B with high bootstrap support values (88/85) (Fig. 1). Moreover, Wolbachia strains detected from K. rhusicola and S. chinensis formed distinct Wolbachia lineage analogous to Wolbachia supergroup $O$ based on gatB and $f b p A$ sequences with high bootstrap (100/100, 100/96) (Figs. 2, 3). Wolbachia strains detected from $P$. yunnanensis clustered within supergroup B with moderate bootstrap support $(88 / 85)$ based on partial $16 S$ rRNA gene sequences, and on $\operatorname{cox} A, h c p A$ and $f t s Z$ gene sequences with high or moderate bootstrap $(99 / 98,87 / 78,98 / 99)$ (Figs. 4, 5, 6).

\section{Discussion}

There are 16 supergroups of Wolbachia that have been identified in insects at present ${ }^{3-5}$. Four of them, named supergroup A, B, M and N, have been detected in aphids. So far Wolbachia was detected mostly in free-living aphids $^{3,4}$. In our study, supergroup $\mathrm{O}$ and B were detected from three galling aphid species, including K. rhusicola, S. chinensis and P. yunnanensis. Supergroup $\mathrm{O}$ has not been reported from aphids before our study. Supergroup $\mathrm{O}$ from these two galling aphids was clustered with the supergroup $\mathrm{O}$ from a whitefly, forming a distinct Wolbachia lineage, which is analogous to the linkage formed based on gat $B$ and $f b p A$ gene sequences with robust bootstrap values (Figs. 1, 2, 3).

The relation between aphids and their facultative symbiont Wolbachia can be affected by different factors such as the ability of symbionts to spread from aphids to aphids within or across populations, the cost of infection for hosts, and aphid living environments (host plant, natural enemy pressure, or temperature) ${ }^{32,33}$. Compared to non-galling aphids, most life stages of galling aphids are in closed microenvironments ${ }^{21,23}$. Generally, hundreds to thousands of aphid individuals living in a gall are produced parthenogenetically by a single fundatrix ${ }^{19,21,34}$. If a fundatrix did not carry Wolbachia before she induces a gall, its offspring have basically no chance to be infected by Wolbachia in an enclosed environment. This means that Wolbachia can hardly spread across galling aphid populations. Moreover, galling aphids receive less pressure from natural enemies than non-galling aphids since they are protected by the gall wall ${ }^{20,35}$. Although vertical transfer is the predominant mode for Wolbachia, horizontal transfer also appeared in nature by infrequently. Horizontal transfer of Wolbachia was observed when infected and uninfected larvae of Trichogramma wasps shared the same hosts ${ }^{31}$. Also, Hymenopteran parasitoids of frugivorous Drosophila acquired Wolbachia through horizontal transmission with high frequency ${ }^{36}$. The three galling aphids in our study are host alternation, so they may readily acquire Wolbachia when they free-living on the secondary hosts by shared the same host mosses or attacked by parasitoid wasps which carried Wolbachia. All aphid samples of our study were collected from closed galls, so they are quite different in their living environments, natural enemy pressures and host plants compared to non-galling aphids ${ }^{20,21,34}$. This is probably the reason why they harbor Wolbachia strains or supergroups different to those in free-living aphids ${ }^{3,4}$.

Many marker genes have been used to detect Wolbachia in insects, but the consistency of these markers varies among different insect species ${ }^{37-39}$. The most conserved marker gene among different Wolbachia strains is the $16 S$ rRNA gene, which also provides more consistent PCR amplification. However, because the $16 S$ rRNA gene is highly conserved, non-target amplification occurs during PCR amplification ${ }^{5}$. The $w s p$ gene evolves faster among different Wolbachia strains. Therefore, PCR amplification is not highly consistent with current primer pairs ${ }^{7}$. In this study, the primers for the $16 S$ rRNA, gat $B$ and $f b p A$ genes could detect Wolbachia in some galling aphid populations. However, primers for the coxA, $h c p A$ and $f t s Z$ genes detected Wolbachia only in P. yunnanensis (Table 1). Primers for the wsp, groEL and gltA genes did not detect Wolbachia in any samples, indicating that the primer regions in these genes varied and the primers could not achieve specific PCR amplifications. Our results also revealed that Wolbachia in the galling aphids was more difficult to detect using the existing primers possibly because of the variation in the sequences of target genes in the Wolbachia strains. Thus, the selection of more efficient and specific Wolbachia gene primers is needed to advance future research on Wolbachia analyses in aphids, especially in galling aphids. 


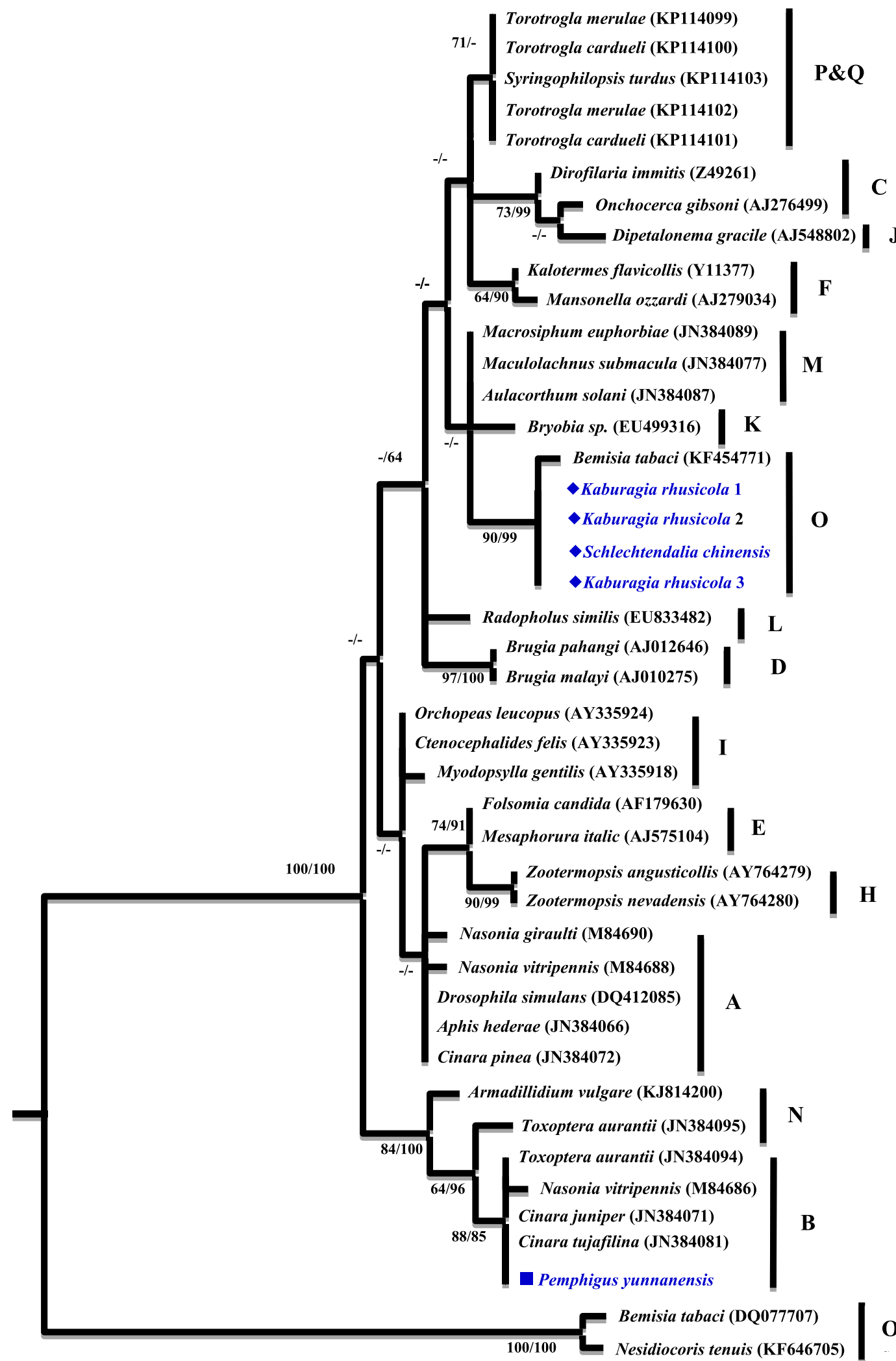

Outgroup

0.02

Figure 1. Phylogenetic analysis inferred from Wolbachia $16 S$ rRNA gene sequences using Maximum Likelihood (ML) and Bayesian Inference (BI). Scale bar indicates substitutions per site. Aphid K. rhusicola and S. chinensis indicated by 'filled diamonds', and P. yunnanensis indicated by 'filled squares.' '-' indicated support rate less than $50 \%$. 


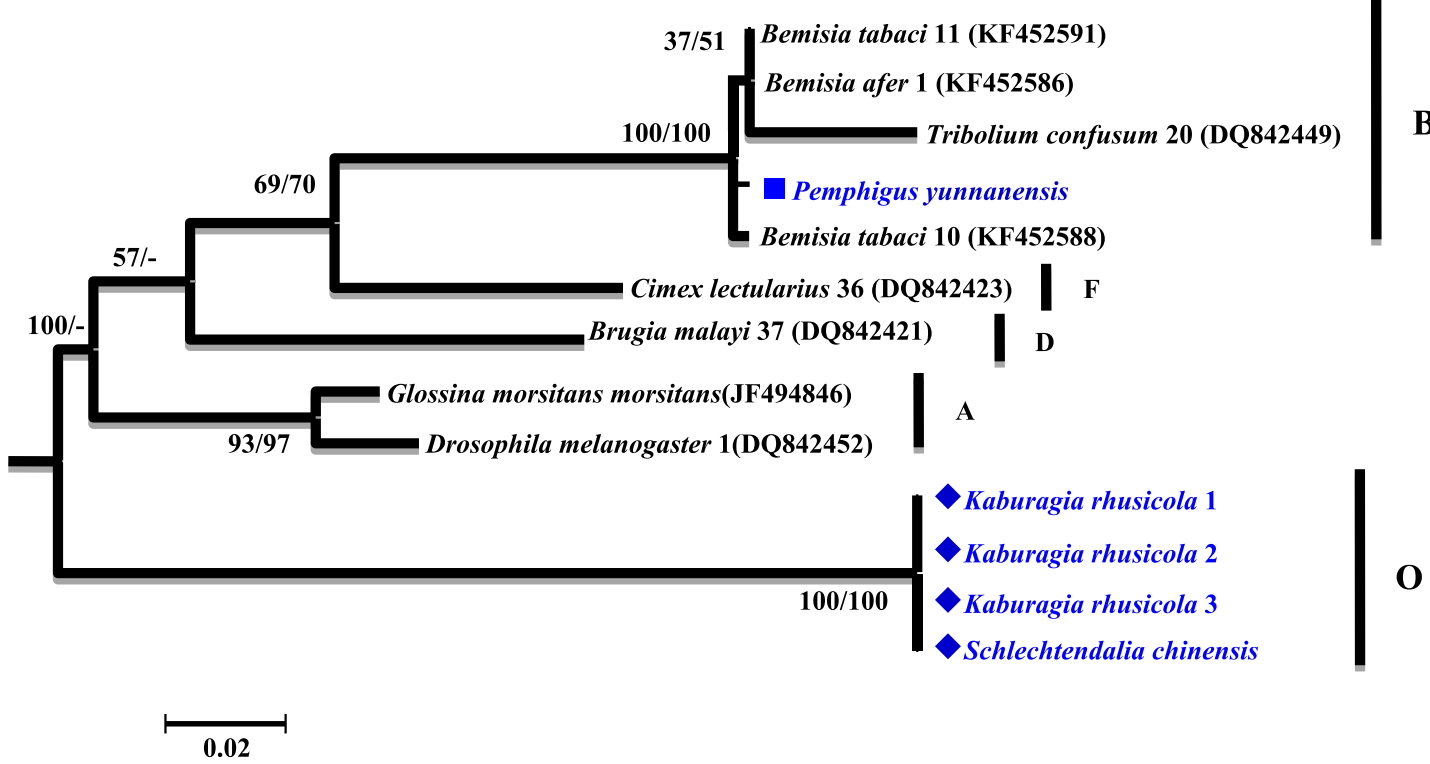

Figure 2. Phylogenetic analysis inferred from Wolbachia gatB gene sequences using Maximum Likelihood (ML) and Bayesian Inference (BI). Scale bar indicates substitutions per site. Aphid K. rhusicola and S. chinensis indicated by 'filled diamonds', and P. yunnanensis indicated by 'filled squares.' '-' indicated support rate less than $50 \%$.

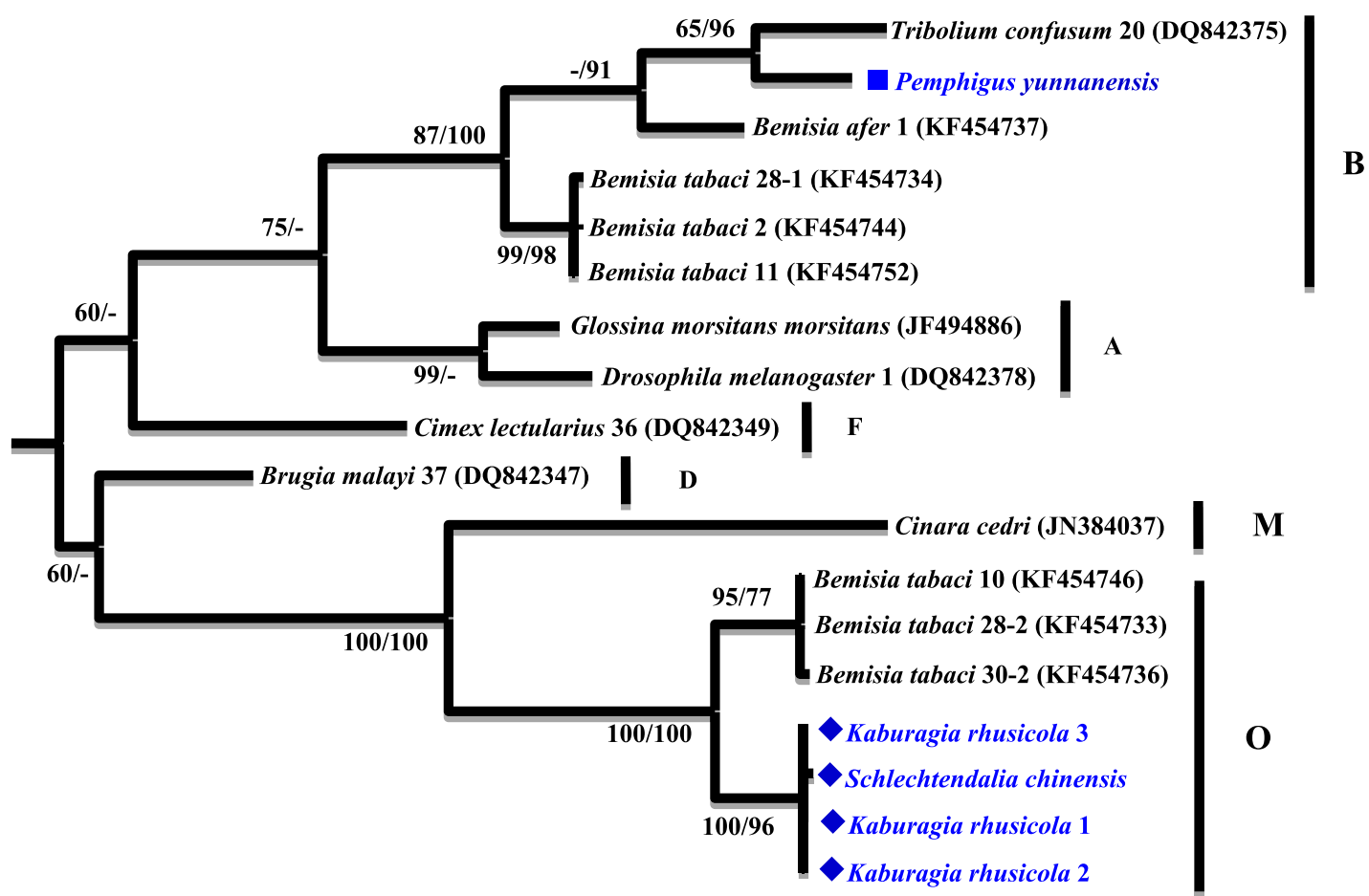

Figure 3. Phylogenetic analysis inferred from Wolbachia $f b p A$ gene sequences using Maximum Likelihood (ML) and Bayesian Inference (BI). Scale bar indicates substitutions per site. Aphid K. rhusicola and S. chinensis indicated by 'filled diamonds', and P. yunnanensis indicated by 'filled squares.' '-' indicated support rate less than $50 \%$. 

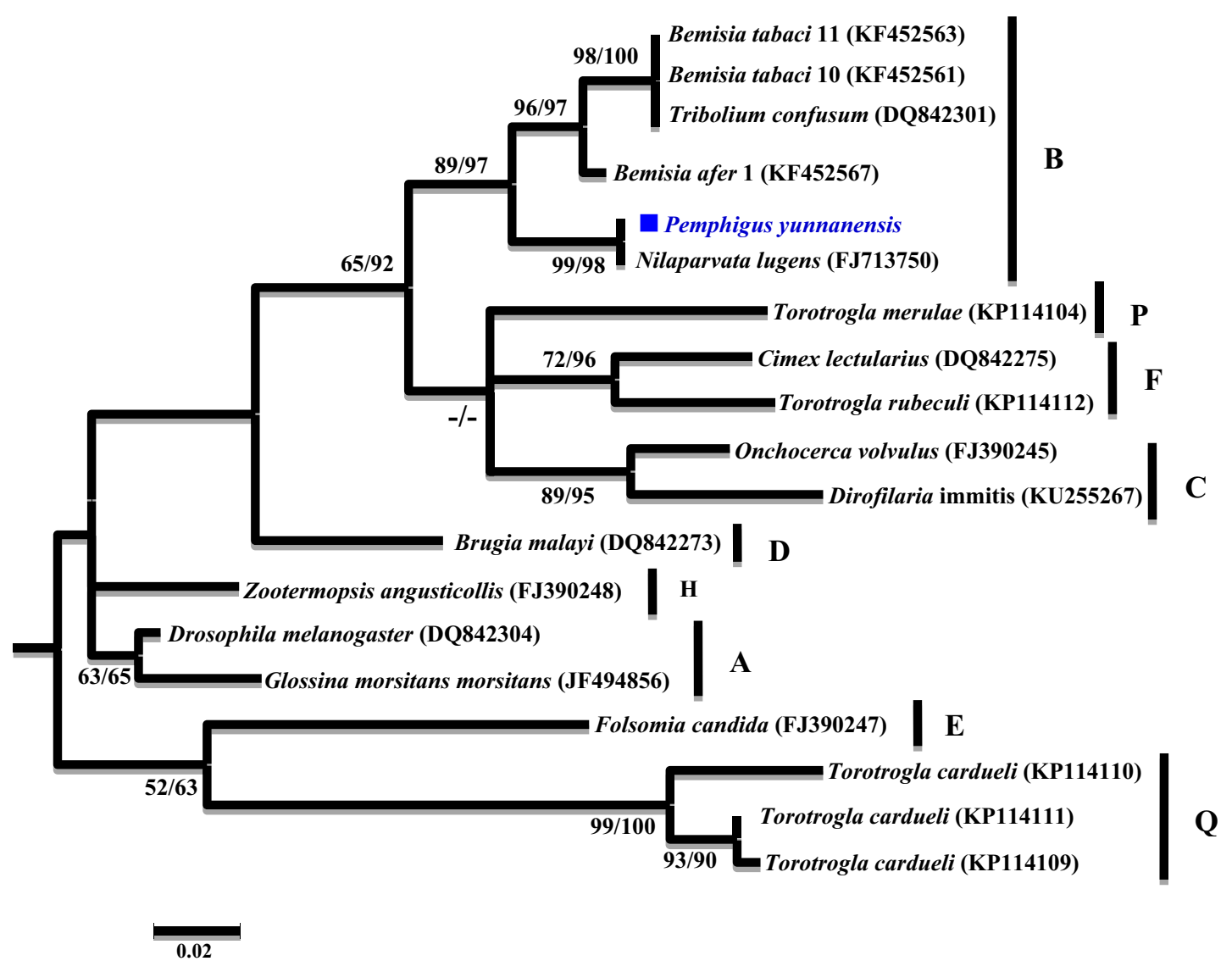

Figure 4. Phylogenetic analysis inferred from Wolbachia coxA gene sequences using Maximum Likelihood (ML) and Bayesian Inference (BI). Scale bar indicates substitutions per site. Aphid P. yunnanensis indicated by 'filled squares.' '-' indicated support rate less than $50 \%$.

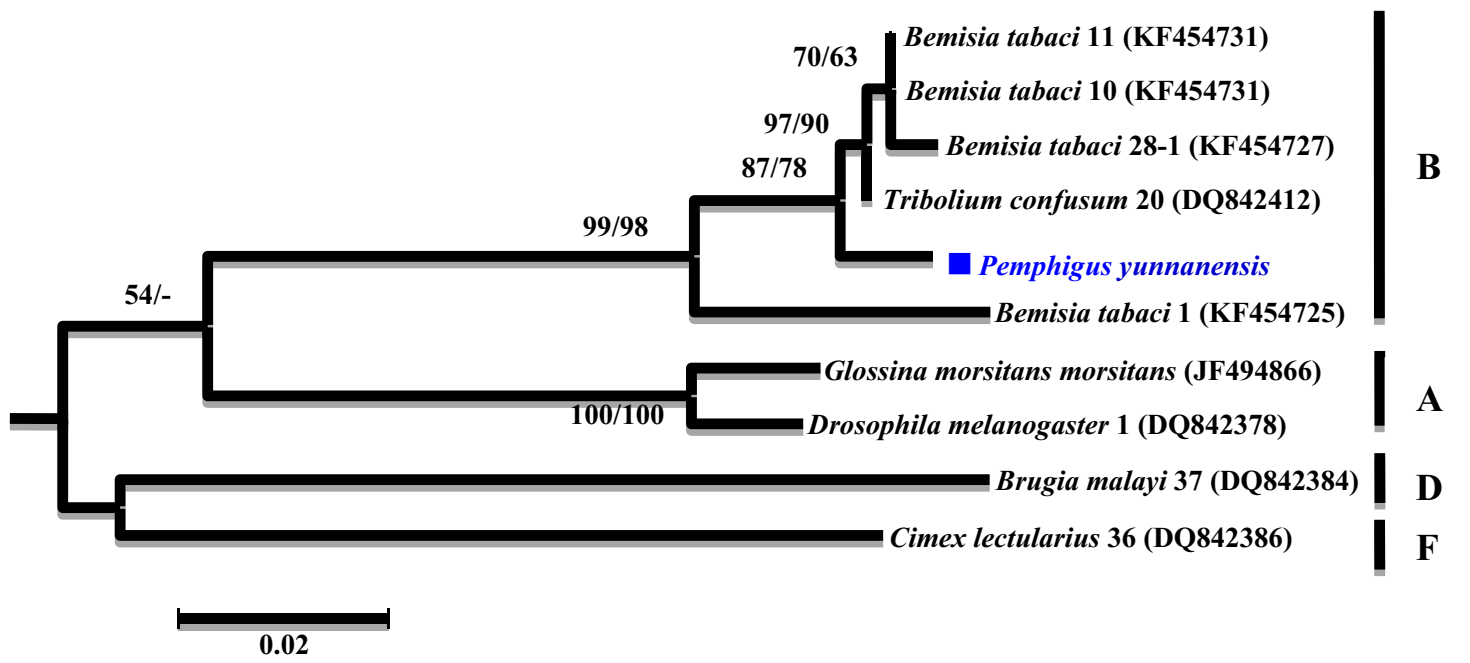

Figure 5. Phylogenetic analysis inferred from Wolbachia hcpA gene sequences using Maximum Likelihood (ML) and Bayesian Inference (BI). Scale bar indicates substitutions per site. Aphid P. yunnanensis indicated by 'filled squares.' '-' indicated support rate less than $50 \%$.

\section{Materials and methods}

Aphid sample collection. Aphids of each population were collected from a mature gall. Fresh aphid galls were collected from host plants manually and dissected in the lab. Aphids were transferred to an Eppendorf tube from a gall, placed in $100 \%$ ethanol and then stored at $-20^{\circ} \mathrm{C}$ until DNA extraction. Galls collected from each location within ten meters were treated as the same population. Since three generations of aphids are produced 


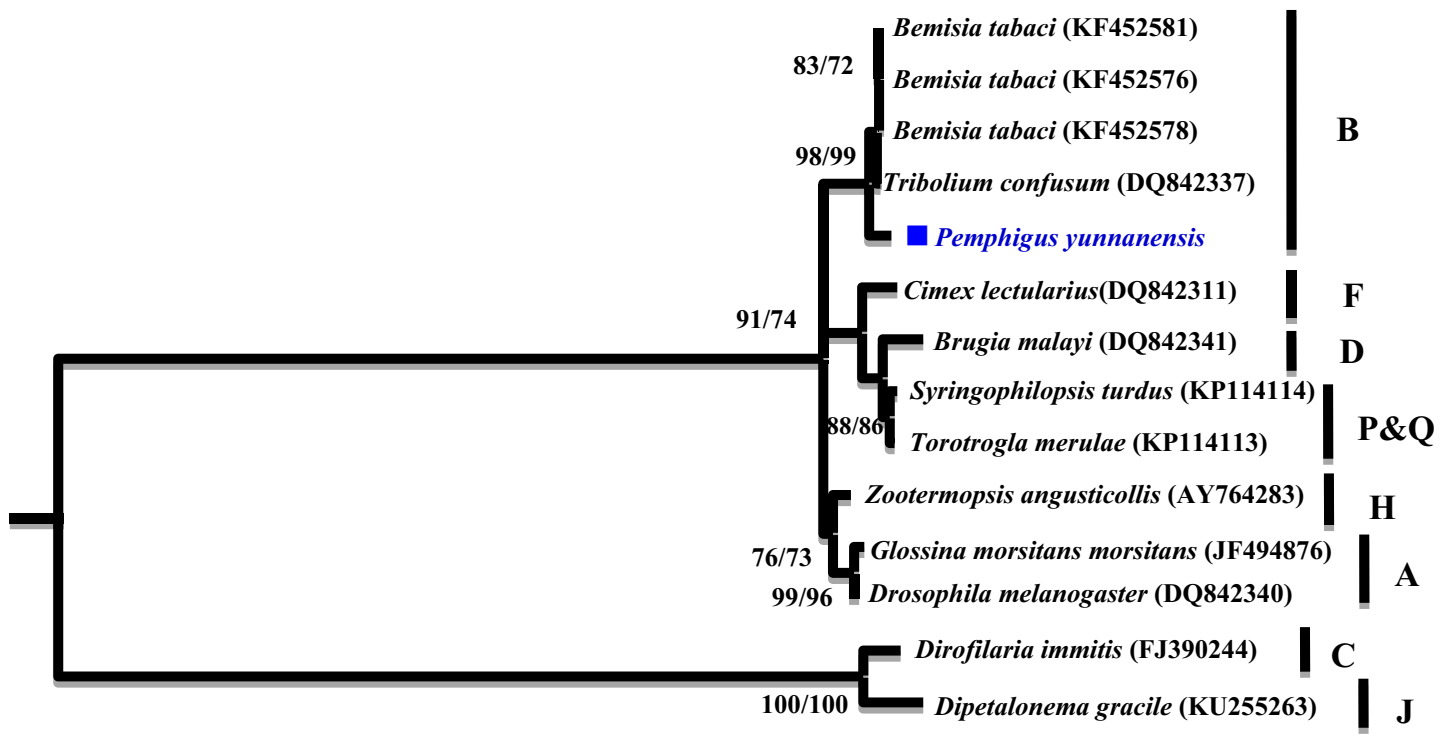

Figure 6. Phylogenetic analysis inferred from Wolbachia ftsZ gene sequences using Maximum Likelihood (ML) and Bayesian Inference (BI). Scale bar indicates substitutions per site. Aphid P. yunnanensis indicated by 'filled squares.' '-' indicated support rate less than $50 \%$.

parthenogenetically by a mating female in a gall to achieve hundreds to thousands of offspring, aphids from a gall were treated as a clone. Galls collected from a location outside $10 \mathrm{~m}$ were treated as different populations.

Nine galling aphid species (Aphididae: Eriosomatinae: Fordini and Pemphigini) were collected from five host trees at eight locations in Yunnan, Sichuan, Hubei and Shaanxi provinces of China. K. rhusicola was the most common species and five populations were obtained from this species. S. chinensis was the second common species with three populations collected. The other six galling aphid species included Floraphis meitanensis, Schlechtendalia peitan, Pemphigus yangcola, Pemphigus yunnanensis, Pemphigus populitransversus and Chaetogeoica folidentata, each with only one population collected (Table 1).

DNA extraction. Ten to twenty aphid individuals of a population were selected for DNA extraction. Genomic DNA was extracted using Dzup Genomic DNA Isolation Reagent (Sangon Biotech, China) from pooled aphids of the same clone following the manufacturer's protocol and was then stored at $-20{ }^{\circ} \mathrm{C}$ until detected.

Wolbachia detection. DNA samples of 117 natural galling aphid populations were screened for the presence of Wolbachia strains. Detection was based on the amplification of the 16S rRNA gene fragment (about 1,100 bp) with the Wolbachia-specific primers 16S 281F 5'-CTATAGCTGATCTGAGAGGAT-3' and 16S 1372R $5^{\prime}$-YGCTTCGAGTGAAACCAATTC-3' (Table 3) $)^{4}$. PCR procedures were an initial step of $94^{\circ} \mathrm{C}$ for $3 \mathrm{~min}$, followed by 35 cycles of $94^{\circ} \mathrm{C}$ for $45 \mathrm{~s}, 55^{\circ} \mathrm{C}$ for $60 \mathrm{~s}$, and $72{ }^{\circ} \mathrm{C}$ for $90 \mathrm{~s}$ and a final step of $72{ }^{\circ} \mathrm{C}$ for $10 \mathrm{~min}$. Amplified DNA products were electrophoresed on agarose gels and stained. PCR products were sequenced from both directions in an ABI 3730 DNA analyzer (Applied Biosystems, Foster City, CA, USA). Sequencing results were then checked by Blast in NCBI nr database (https://blast.ncbi.nlm.nih.gov/Blast.cgi). Only those samples, which were blasted to expected products of the specific primers, were selected for further analysis. These selected samples were further examined by PCR analyses of the genes $g l t A, \operatorname{groEL}, w s p, \operatorname{gat} B, f b p A, \operatorname{cox} A, h c p A$ and $f t s Z$ using specific primers based on previous reports (Table 3$)^{40-43}$. PCR amplifications were carried out in $25 \mu l$ reaction volume, consisting of $1 \mu \mathrm{l} \mathrm{DNA,} 1 \mu \mathrm{l}$ of forward and reverse primers $(10 \mu \mathrm{mol} / \mathrm{l}), 12.5 \mu \mathrm{l} \mathrm{Taq} \mathrm{Master} \mathrm{Mix} \mathrm{(Sangon}$ Biotech, China), and $9.5 \mu \mathrm{lddH_{2 }}$ O. PCR products $(4 \mu \mathrm{l})$ were electrophoresed on a $1.5 \%$ agarose gel. Positive samples were further analyzed.

Sequencing. Nine genes $16 S$ rRNA, gltA, groEL, wsp, gat B, fbpA, coxA, hcpA and ftsZ of Wolbachia were amplified and sequenced from the populations harboring Wolbachia. PCR products were sequenced from both directions in an ABI 3730 DNA analyzer. Original sequences were manually processed and then assembled by DNA Star Lasergene v7.1-SeqMan.

Nucleotide sequence accession numbers. Twelve gene sequences of $16 S r R N A, g l t B, f b p A, \operatorname{cox} A$, $h c p A$ and $f t s Z$ generated in this study have been deposited in the GenBank database under accession numbers MT554837-MT554842 and MT634226-MT634228. 


\begin{tabular}{|c|c|c|c|c|c|}
\hline Gene & Hypothetical product & $\begin{array}{l}\text { Primer name and sequences } \\
\left(5^{\prime}-3^{\prime}\right)\end{array}$ & Product size & $\operatorname{Tm}\left({ }^{\circ} \mathrm{C}\right)$ & References \\
\hline $16 S r R N A$ & Ribosomal RNA 16S & $\begin{array}{l}\text { 16S 281F: CTATAGCTGATC } \\
\text { TGAGAGGAT } \\
\text { 16S 1372R: YGCTTCGAGTGA } \\
\text { AACCAATTC }\end{array}$ & 1,100 & 55 & Wang et al. ${ }^{4}$ \\
\hline $16 S r R N A$ & Ribosomal RNA 16S & $\begin{array}{l}\text { WspecF: CAT ACC TAT TCG } \\
\text { AAG GGA TAG } \\
\text { WspecR: AGC TTC GAG TGA } \\
\text { AAC CAA TTC }\end{array}$ & 440 & 52 & Werren and Windsor ${ }^{43}$ \\
\hline$w s p$ & Outer surface protein & $\begin{array}{l}\text { Wsp81F: TGGTCCAATAAG } \\
\text { TGATGAAGAAAC } \\
\text { Wsp691R: AAAAATTAA ACG } \\
\text { CTACTCCA } \\
\end{array}$ & 546 & 52 & Zhou and Rousset ${ }^{40}$ \\
\hline groEL & Chaperonin GroEL & $\begin{array}{l}\text { GroELF: GGTGAGCAGTTR } \\
\text { CARSAAGC } \\
\text { GroELR: TARCCRCGRTCA } \\
\text { AAYTGCATRCCA }\end{array}$ & 491 & 55 & Wang et al. ${ }^{4}$ \\
\hline$f t s Z$ & Cell division protein & $\begin{array}{l}\text { FtsZF: GTTGGYAAAGGTGCA } \\
\text { GCAGAAGA } \\
\text { FtsZR: CGYACYCATTTKGCT } \\
\text { GCAGMATCAA }\end{array}$ & 524 & 53 & Wang et al. ${ }^{4}$ \\
\hline groEL & Chaperonin GroEL & $\begin{array}{l}\text { groEL F1: GGTGAGCAGTTG } \\
\text { CAAGAAGC } \\
\text { groEL R1: AGRTCTTCCATY } \\
\text { TTRATTCC } \\
\end{array}$ & 491 & 55 & Casiraghi et al. ${ }^{41}$ \\
\hline gltA & Citrate synthase & $\begin{array}{l}\text { gltAF1: TACGATCCAGGGTTT } \\
\text { GTTTCTAC } \\
\text { gltAR1: CTCATTAGCTCCACC } \\
\text { GTGTG }\end{array}$ & 659 & 56 & Casiraghi et al. ${ }^{41}$ \\
\hline gat B & $\begin{array}{l}\text { Glutamyl-tRNA(Gln) ami- } \\
\text { dotransferase, subunit B }\end{array}$ & $\begin{array}{l}\text { GatB F1: GAKTTAAAYCGY } \\
\text { GCAGGBGTT } \\
\text { GatB R1: TGGYAAYTCRGG } \\
\text { YAAAGATGA } \\
\end{array}$ & 497 & 54 & Paraskevopoulos et al. ${ }^{42}$ \\
\hline $\operatorname{cox} A$ & Cytochrome coxidase, subunit I & $\begin{array}{l}\text { CoxA-F1: TTGGRGCRATYA } \\
\text { ACTTTATAG } \\
\text { CoxA-R1: CTAAAGACTTT- } \\
\text { KACRCCAGT }\end{array}$ & 488 & 55 & Paraskevopoulos et al. ${ }^{42}$ \\
\hline$h c p A$ & Conserved hypothetical protein & $\begin{array}{l}\text { HcpA-F1: GAAATARCAGTT } \\
\text { GCTGCAAA } \\
\text { HcpA-R1: GAAAGTYRAGCA } \\
\text { AGYTCTG }\end{array}$ & 515 & 53 & Paraskevopoulos et al. ${ }^{42}$ \\
\hline$f b p A$ & Fructose-bisphosphate aldolase & $\begin{array}{l}\text { FbpA-F1: GCTGCTCCRCTT } \\
\text { GGYWTGAT } \\
\text { FbpA-R1: CCRCCAGARAAA } \\
\text { AYYACTATTC }\end{array}$ & 509 & 59 & Paraskevopoulos et al. ${ }^{42}$ \\
\hline
\end{tabular}

Table 3. Primer list used for Wolbachia detection.

Sequence alignment and phylogenetic analysis. Genes representative of Wolbachia strains from different supergroups were selected from the NCBI database (https://www.ncbi.nlm.nih.gov), and used to classify Wolbachia strains detected in our aphid samples. Sequence alignments were carried out using ClustalX $1.83^{44}$. Maximum likelihood (ML) and Bayesian inference (BI) were used for phylogenetic analysis. The ML analysis was carried out with MEGA 6.0 and node support rates were evaluated with 1,000 bootstrap replicates. The Bayesian inference (BI) method was performed in MrBayes 3.1.2 $2^{45}$. In MrBayes, four chains (one cold and three heated chains) which were run for 4 million generations. Trees were sampled every 100 generations, and the first $25 \%$ of samples were discarded as burn-in. From the remaining trees, $50 \%$ majority-rule consensus trees were generated. Posterior probabilities were computed from the remaining trees. To obtain the appropriate evolution model, the parameters were evaluated using the Akaike Information Standard (AIC) in MrModeltest $2.3^{46}$. Using this method, the following gene models were obtained: the HKY $+\mathrm{G}$ model of $16 \mathrm{~S} r R N A$ gene, the GTR $+\mathrm{G}$ model of $f t s Z$ gene, the $\mathrm{HKY}+\mathrm{G}$ model of $\operatorname{coxA}$ gene, the $\mathrm{GTR}+\mathrm{I}+\mathrm{G}$ model of gat $B$ gene and the $\mathrm{HKY}+\mathrm{G}$ model of $f b p A$ gene.

Received: 9 December 2019; Accepted: 3 July 2020

Published online: 21 July 2020

\section{References}

1. Werren, J. H. Biology of Wolbachia. Annu. Rev. Entomol. 42, 587-609 (1997).

2. Stouthamer, R., Breeuwer, J. A. \& Hurst, G. D. Wolbachia pipientis: microbial manipulator of arthropod reproduction. Annu. Rev. Microbiol. 53, 71-102 (1999).

3. Augustinos, A. A. et al. Detection and characterization of Wolbachia infections in natural populations of aphids is the hidden diversity fully unraveled. PLoS ONE 6, e28695 (2011). 
4. Wang, Z., Su, X. M., Wen, J., Jiang, L. Y. \& Qiao, G. X. Widespread infection and diverse infection patterns of Wolbachia in Chinese aphids. Insect Sci. 21, 313-325 (2014).

5. Bing, X. L. et al. Diversity and evolution of the Wolbachia endosymbionts of Bemisia (Hemiptera: Aleyrodidae) whiteflies. Ecol. Evol. 13, 2714-2737 (2014).

6. Glowska, E., Dragun-Damian, A., Dabert, M. \& Gerth, M. New Wolbachia supergroups detected in quill mites (Acari: Syringophilidae). Infect. Genet. Evol. 30, 140-146 (2015).

7. Baldo, L. et al. Multilocus sequence typing system for the endosymbiont Wolbachia pipientis. Appl. Environ. Microbiol. 72, 7098$7110(2006)$.

8. Rigaud, T. et al. Feminizing endocytobiosis in the terrestrial crustacean Armadillidium vulgare Latr. (Isopoda): recent acquisitions. Endocytobiosis Cell Res. 7, 259-273 (1991).

9. Gdd, H., Men, M. \& Walker, L. E. The importance of cytoplasmic male killing elements in natural populations of the two spot ladybird, Adalia bipunctata (Linnaeus) (Coleoptera: Coccinellidae). Biol. J. Linn. Soc. 49, 195-202 (1993).

10. Stouthamer, R., Breeuwer, J. A. J., Luck, R. F. \& Werren, J. H. Molecular identification of microorganisms associated with parthenogenesis. Nature 361, 66-68 (1993).

11. Werren, J. H., Baldo, L. \& Clark, M. E. Wolbachia: master manipulators of invertebrate biology. Nat. Rev. Microbiol. 6, 741-751 (2008).

12. Hedges, L. M., Brownlie, J. C., O’Neill, S. L. \& Johnson, K. N. Wolbachia and virus protection in insects. Science 322, 702-702 (2008).

13. Moreira, L. A. et al. Wolbachia symbiont in Aedes aegypti limits infection with dengue, Chikungunya, and Plasmodium. Cell 7, 1268-1278 (2009).

14. Mcmeniman, C. J. et al. Stable introduction of a life-shortening Wolbachia infection into the mosquito Aedes aegypti. Science 323, $141-144$ (2009).

15. Hosokawa, T., Koga, R., Kikuchi, Y., Meng, X. Y. \& Fukatsu, T. Wolbachia as a bacteriocyte-associated nutritional mutualist. Proc. Natl. Acad. Sci. 107, 769-774 (2010).

16. Fast, E. M. et al. Wolbachia enhances Drosophila stem cell proliferation and target the germline stem cell niche. Science 334, 990-992 (2011).

17. Bourtzis, K. Wolbachia-based technologies for insect pest population control. Adv. Exp. Med. Biol. 627, 104-113 (2008).

18. Blackman, R. L. \& Eastop, V. F. Aphids on the World's herbaceous plants and shrubs (Wiley, West Sussex, 2006).

19. Zhang, G. X., Qiao, G. X., Zhong, T. S. \& Zhang, W. Y. Fauna Sinica Insecta 14, Homoptera, Mindaridae and Pemphigidae (Science Press, Beijing, 1999).

20. Wool, D. Galling aphids: specialization, biological complexity, and variation. Annu. Rev. Entomol. 49, 175-192 (2004).

21. Stone, G. N. \& Schonrogge, K. The adaptive significance of insect gall morphology. Trends Ecol. Evol. 18, 512-522 (2003).

22. Schultz, J. C., Edger, P. P., Body, M. J. A. \& Appel, H. M. A galling insect activates plant reproductive programs during gall development. Sci. Rep. 9, 1833 (2019).

23. Moran, N. A. The evolution of aphid life cycles. Annu. Rev. Entomol. 37, 321-348 (1992).

24. Zhang, G. X. \& Zhong, T. S. Economic insect fauna of China. 25 Homoptera: Aphidinea (Science Press, Beijing, 1983).

25. Yang, Z. X. High yield cultivation techniques of Chinese Gallnut (China Forestry Publishing House, Beijing, 2011).

26. Jeyaprakash, A. \& Hoy, M. A. Long PCR improves Wolbachia DNA amplification: wsp sequences found in $76 \%$ of sixty-three arthropod species. Insect Mol. Biol. 9, 393-405 (2000).

27. Tsuchida, T., Koga, R., Shibao, H., Matsumoto, T. \& Fukatsu, T. Diversity and geographic distribution of secondary endosymbiotic bacteria in natural populations of the pea aphid, Acyrthosiphon pisum. Mol. Ecol. 11, 2123-2135 (2002).

28. Gomez-Valero, L. et al. Coexistence of Wolbachia with Buchnera aphidicola and a secondary symbiont in the aphid Cinara cedri. J. Bacteriol. 86, 6626-6633 (2004).

29. Wang, Z., Shen, Z. R., Song, Y., Liu, H. Y. \& Li, Z. X. Distribution and diversity of Wolbachia in different populations of the wheat aphid Sitobion miscanthi (Hemiptera: Aphididae) in China. Eur. J. Entomol. 106, 49-55 (2009).

30. Reuter, M. \& Keller, L. High levels of multiple Wolbachia infection and recombination in the ant Formica exsecta. Mol. Biol. Evol. 20, 748-753 (2003).

31. Huigens, M. E. et al. Natural interspecific and intraspecific horizontal transfer of parthenogenesis-inducing Wolbachia in Trichogramma wasps. Proc. R. Soc. Lond. B. 271, 509-515 (2004).

32. Guo, J. et al. Nine facultative endosymbionts in aphids. A review. J. Asia-Pac. Entomol. 21, 794-801 (2017).

33. De Clerck, C. et al. A metagenomic approach from aphid's hemolymph sheds light on the potential roles of co-existing endosymbionts. Microbiome 3, 1-11 (2015).

34. Shao, S. X., Yang, Z. X. \& Chen, X. M. Gall development and clone dynamics of the galling aphid Schlechtendalia chinensis (Hemiptera: Pemphigidae). J. Econ. Entomol. 106, 1628-1637 (2012).

35. Oliver, K. M. et al. Facultative symbionts in aphids and the horizontal transfer of ecologically important traits. Annu. Rev. Entomol. 55, 247-266 (2010).

36. Vavre, F., Fleury, F., Lepetit, D., Fouillet, P. \& Boulétreau, M. Phylogenetic evidence for horizontal transmission of Wolbachia in host-parasitoid associations. Mol. Biol. Evol. 16, 1711-1723 (1999).

37. Gerth, M. Classification of Wolbachia (Alphaproteobacteria, Rickettsiales): No evidence for a distinct supergroup in cave spiders. Infect. Genet. Evol. 43, 378-380 (2016).

38. Lefoulon, E. et al. Breakdown of coevolution between symbiotic bacteria Wolbachia and their filarial hosts. PeerJ 4, e1840 (2016).

39. Bleidorn, C. \& Gerth, M. A critical re-evaluation of multilocus sequence typing (MLST) efforts in Wolbachia. FEMS Microbiol. Ecol. https://doi.org/10.1093/femsec/fix163 (2018).

40. Zhou, W., Rousset, F. \& O’Neill, S. Phylogeny and PCR-based classification of Wolbachia strains using wsp gene sequences. Proc. R. Soc. Lond. B. 265, 509-515 (1998).

41. Casiraghi, M. et al. Phylogeny of Wolbachia pipientis based on gltA, groEL and ftsZ gene sequences: clustering of arthropod and nematode symbionts in the F supergroup, and evidence for further diversity in the Wolbachia tree. Microbiology 151, 4015-4022 (2005).

42. Paraskevopoulos, C., Bordenstein, S. R., Wernegreen, J. J., Werren, J. H. \& Bourtzis, K. Toward a Wolbachia multilocus sequence typing system: discrimination of Wolbachia strains present in Drosophila species. Curr. Microbiol. 53, 388-395 (2006).

43. Werren, J. H. \& Windsor, D. M. Wolbachia infection frequencies in insects: evidence of a global equilibrium? Proc. Biol. Sci. 267, $1277-1285(2000)$.

44. Thompson, J. D., Gibson, T. J., Plewniak, F., Jeanmougin, F. \& Higgins, D. G. The CLUSTAL_X windows interface: flexible strategies for multiple sequence alignment aided by quality analysis tools. Nucleic Acids Res. 25, 4876-4882 (1997).

45. Ronquist, F. \& Huelsenbeck, J. P. MRBAYES 3: Bayesian phylogenetic inference under mixed models. Bioinformatics 19, 1572-1574 (2003).

46. Nylander, J. A. A. MrModeltest v2.2. Program distributed by the author (Evolutionary Biology Centre, Uppsala University, Uppsala, 2004). 


\section{Acknowledgements}

This project was supported by the National Natural Science Foundation of China (31872305; U1402263), the National Key R \& D Program of China (2018YFD0600403), and the grant for Innovative Team of 'Insect Molecular Ecology and Evolution' of Yunnan Province. We thank to Prof. Ming-Shun Chen, Kansas State University, and Prof. Kirst King-Jones, University of Alberta, for their helpful comments.

\section{Author contributions}

Z.Y and X.C designed and led the project. W.R collected samples, carried out experiments. W.R and Z.Y analyzed the data and wrote the manuscript. W.R, H.W, Y.Y, S.S and H.W designed Figures. All authors reviewed the manuscript. The manuscript is approved by all authors for publication.

\section{Competing interests}

The authors declare no competing interests.

\section{Additional information}

Correspondence and requests for materials should be addressed to Z.Y.

Reprints and permissions information is available at www.nature.com/reprints.

Publisher's note Springer Nature remains neutral with regard to jurisdictional claims in published maps and institutional affiliations.

(c) (i) Open Access This article is licensed under a Creative Commons Attribution 4.0 International cc) License, which permits use, sharing, adaptation, distribution and reproduction in any medium or format, as long as you give appropriate credit to the original author(s) and the source, provide a link to the Creative Commons license, and indicate if changes were made. The images or other third party material in this article are included in the article's Creative Commons license, unless indicated otherwise in a credit line to the material. If material is not included in the article's Creative Commons license and your intended use is not permitted by statutory regulation or exceeds the permitted use, you will need to obtain permission directly from the copyright holder. To view a copy of this license, visit http://creativecommons.org/licenses/by/4.0/.

(C) The Author(s) 2020 